\title{
O trabalho com línguas para fins específicos em uma perspectiva interacionista sociodiscursiva ${ }^{1}$
}

\section{The work with languages for specific purposes in a sociodiscursive interactionist perspective}

Ana Paula Marques Beato-Canato*
Universidade Federal do Rio de Janeiro
Rio de Janeiro - Rio de Janeiro / Brasil

RESUMO: Aparentemente em caminho oposto à proposta de ensino de línguas para fins específicos, que pressupõe rapidez, o interacionismo sociodiscursivo (ISD) (BRONCKART, 2003; 2006; 2008; SCHNEUWLY, DOLZ, 2004) postula um trabalho processual, organizado em sequências didáticas que visam o desenvolvimento de capacidades de linguagem necessárias para agir em contextos específicos. Esse trabalho pode demandar diversas horas de estudo em torno de um gênero textual específico para garantir que a língua seja compreendida como prática social e o texto como instrumento semiótico para agir nesses contextos. Alinhado a essa perspectiva, os desafios deste artigo são analisar e exemplificar as adaptações possíveis e necessárias na proposta didática genebrina para que possa ser aplicada em contextos de ensino-aprendizagem de línguas para fins específicos. PALAVRAS-CHAVE: processo ensino-aprendizagem de línguas para fins específicos, interacionismo sociodiscursivo, capacidades de linguagem, sequências didáticas.

ABSTRACT: While the Language for Specific Purposes approach presupposes velocity, the sociodiscursive interactionism theory (BRONCKART, 2003; 2006; 2008; SCHEUWLY; DOLZ, 2004) postulates a processual work, organized in didactic sequences which aim at the development of language capacities necessary to act in particular contexts. This perspective requires several hours of study focused on a given textual genre to ensure the comprehension of language as a social practice and of text as a semiotic instrument, which allows effective verbal

*anabeato@uol.com.br

${ }^{1}$ Gostaria de agradecer à Natalia Labella Sánchez (IFRS - Campus Porto Alegre) pela leitura crítica do texto e sugestôes dadas. O conteúdo do texto é, no entanto, de minha inteira responsabilidade. 
communication in singular situations. Aligned with this perspective, the challenges of this paper are to analyze and illustrate possible and necessary adjustments in the Swiss proposal that can be applied to the learning-teaching process of languages for specific purposes.

KEYWORDS: learning-teaching process of languages for specific purposes, sociodiscursive interactionism, language capacities, didactic sequences.

\section{Introdução}

A língua inglesa compõe o currículo da maioria das instituições em todo o território nacional, com carga horária de duas horas semanais nos ensinos fundamental e médio. Isso devido à lei 11.165/2005 em vigor, que exige a oferta de ao menos uma língua estrangeira, considerando que sua aprendizagem pode possibilitar o conhecimento de outras culturas e a melhor compreensão da própria (BRASIL, 1998).

Embora as diretrizes curriculares preconizem uma perspectiva sociointeracional, segundo Almeida Filho (2004), o ensino-aprendizagem de línguas estrangeiras no Brasil ainda tem sido marcado pelo privilégio dado ao estudo da língua pela língua, ou seja, dá-se ênfase à forma gramatical descontextualizada, apresentando-se resultados aquém das expectativas tanto do público em geral quanto do que os especialistas cogitam.

Os pesquisadores têm se preocupado com esses resultados e com a maneira de abordar as línguas estrangeiras de forma que respeitem os valores culturais dos aprendizes e contribuam para "a construção de quem somos em outras bases ao mostrar como somos multiculturais (MOITA LOPES, 2005, p. 60).”

No caso de línguas para fins específicos, a finalidade do trabalho é contribuir para que o aprendiz desenvolva capacidades para agir socialmente em situaçóes acadêmicas e/ou profissionais específicas, o que vai ao encontro do que foi mencionado. $\mathrm{O}$ que geralmente o diferencia é a rapidez exigida dado o curto espaço de tempo disponível para alcançar seus objetivos.

Como pesquisadora na linha do Interacionismo Sociodiscursivo (ISD), ao ingressar como professora de inglês instrumental em uma instituição federal que contribuiu para a expansão da abordagem no Brasil, me questionava até que ponto poderia alcançar os objetivos da disciplina utilizando os princípios e a metodologia que defendia, tendo em vista que, aparentemente em caminho oposto, o ISD (BRONCKART, 2003; 2006; 2008; SCHNEUWLY, DOLZ, 2004; DOLZ; SCHNEUWLY, 2004; CRISTOVÃO, 2009; BEATOCANATO, 2009) propõe um trabalho processual, organizado em sequências 
didáticas (SD) que visam o desenvolvimento de capacidades de linguagem necessárias para agir em contextos específicos. Esse trabalho pode demandar diversas horas de estudo em torno de um gênero textual específico para garantir que a língua seja compreendida como prática social e o texto como instrumento semiótico.

Em três anos de trabalho, procurei compreender com mais precisão os propósitos da disciplina e investigar como a proposta genebrina poderia servir a esse contexto. Este artigo traz algumas reflexões com uma exemplificação de um material didático utilizado com alunos do curso médio-técnico de Química.

O texto está dividido em três partes e na primeira delas, a abordagem instrumental é retomada. Em seguida, alguns princípios do ISD são apresentados e exemplificados com uma SD a respeito de gêneros acadêmicos, mais especificamente do resumo de artigos científicos (abstracts). Para finalizar, algumas considerações são postas, procurando compreender como as diferentes abordagens podem se complementar.

\section{A abordagem instrumental}

Almejando atender à demanda nacional da época, a abordagem instrumental foi introduzida no Brasil na década de 70 e obteve ampla aceitação. Essa inserção foi feita especialmente pelo Projeto Nacional de Inglês Instrumental, liderado pela Professora Dra. Maria Antonieta Alba Celani, então coordenadora do Programa de Linguística Aplicada na Pontifícia Universidade Católica de São Paulo. Ao longo do tempo, talvez por incompreensões teóricas, mitos foram sendo criados a seu respeito, o que fez com que muitos pesquisadores e professores a abandonassem. Todavia, como aponta Ramos (2009, no prelo), até os dias atuais, é possível encontrar a disciplina em muitas instituições, muitos títulos de livros com essa denominação e alguns programas de pósgraduação, o que leva a pesquisadora a concluir que continua presente e influenciando o trabalho com línguas estrangeiras em nosso país (RAMOS, 2009, no prelo).

Em artigo publicado em 2009, Ramos (2009, no prelo) resgata a história da abordagem instrumental no Brasil e, em artigo anterior, publicado em 2005, a estudiosa ocupa-se em desconstruir os mitos em busca da construção de um futuro. Para isso, recupera as características do instrumental, enfatiza as mudanças propostas e retoma a maneira como foi sendo incorporada no processo de ensino-aprendizagem de línguas estrangeiras no Brasil. 
As principais características da abordagem instrumental mencionadas por Ramos (2005; 2009, no prelo) são: a centralização nas necessidades do aluno, que determinam os objetivos e o planejamento do curso; o foco em temas e conteúdos relacionados às áreas de atuação do aprendiz (acadêmicas e / ou profissionais); a visão de língua como meio / instrumento para um desempenho eficaz na situação-alvo; o uso de material autêntico; o trabalho com estratégias de leitura; a organização do curso de modo a contribuir para o desenvolvimento da autonomia do aluno, considerando sua curta duração e a necessidade que o estudante teria de utilizar a língua em situaçôes reais de trabalho ou estudo; o ensino de gramática discursiva; as estratégias de leitura e de aquisição de vocabulário; o trabalho partindo da compreensão geral para a detalhada, valorizando a conscientização; a auto-avaliação; e o uso do português.

Tratando da abordagem instrumental, Holmes (2009) defende que,

Alguns dos grandes impactos deste projeto no Brasil foram: (a) o enfoque com base no processo, o que confere ao projeto sustentabilidade, (b) uma metodologia marcadamente "local" (versus "global"), uma vez que visa necessidades específicas e localizadas, em oposição às "importadas" que pouco se relacionam à realidade específica que vivemos, além de procurar empoderar os recursos humanos existentes, com os recursos materiais disponíveis, (c) uma identidade profissional nova e inovadora, que se contrapõe a do profissional que ensina o "inglês geral", inadequado às premências específicas de grupos especializados; (d) uma mudança contextual radical no modo de se ensinar, se aprender e se conceber a língua inglesa, especialmente no ambiente acadêmico e profissional (HOLMES, 2009, apud ROMERO, 2010, p.30/31).

Em se tratando dos mitos criados ao longo dos anos, Ramos (2005) argumenta que, muitas vezes, a abordagem instrumental é vista como uma perspectiva que foca exclusivamente a leitura de inglês técnico, em aulas totalmente na língua materna, sem abordar a gramática nem permitir o uso do dicionário; sem considerar o indivíduo como um todo, as aulas são realizadas de maneira totalmente pragmática e utilitária, sendo possível apenas quando o aluno já domina o "inglês básico". Segundo a estudiosa (RAMOS, 2005), devido a esses mitos, a abordagem é comumente avaliada como deficiente.

Diante desse cenário e com as demandas emergentes, Ramos (2005) aponta a necessidade de mudanças nos olhares e nos fazeres, o que tem mobilizado estudiosos em diferentes instituiçōes. A pesquisadora (RAMOS, 2009, no prelo) cita vários trabalhos, alguns com o intuito de investigar as 
necessidades profissionais de diferentes áreas; outros de cunho pedagógico, que se ocupam de análise de gêneros e de experiências pedagógicas; e alguns com foco no ambiente virtual, com a investigação de cursos que têm surgido nesse ambiente.

Também posso apontar as pesquisas realizadas por alunos do ensino médio-técnico profissionalizante de um instituto federal que, sob minha orientação e com base nos princípios do Interacionismo Sociodiscursivo, estão mapeando as necessidades profissionais e acadêmicas de cinco cursos da instituição (Alimentos, Biotecnologia, Farmácia, Meio-Ambiente e Química), englobando gêneros textuais e temas, o que poderá servir de embasamento para mudanças nos conteúdos programáticos e na maneira de trabalho. ${ }^{2}$

Para Ramos (2005), a abordagem se diferencia por se basear em pesquisas sobre as necessidades específicas de seu público-alvo e por considerar as seguintes questões: o que se deseja é um curso geral ou para fins específicos? Um curso que prioriza o ensino de estratégias ou de gêneros textuais? A autora (RAMOS, 2004) argumenta que o desafio é o trabalho com gêneros específicos a partir das necessidades dos alunos, uma das bases da Abordagem Instrumental.

Dando continuidade a essa reflexão, a estudiosa discorre sobre a indispensabilidade, do ponto de vista pedagógico, de respeitar o aspecto da gradação e progressão de conteúdo, sem que a aprendizagem seja de elementos fragmentados ou estanques, o que significa reconhecer seus componentes e utilizá-los em situações práticas (RAMOS, 2005).

Em uma perspectiva interacionista sociodiscursiva, é possível postular que trabalhar com necessidades específicas significa focar em gêneros textuais considerados essenciais para determinado grupo e colaborar para a apreensão de suas características contextuais, organizacionais e linguístico-discursivas,

${ }^{2} \mathrm{O}$ projeto $O$ mapeamento de gêneros textuais necessários para agir em contextos profissionais e acadêmicos diversos está sendo desenvolvido por integrantes do grupo de pesquisa Linguagem e Educaçāo para Fins Específicos, cadastrado no CNPq, sob minha liderança; conta com uma bolsista PIBIC Jr. e dois pesquisadores voluntários de cada curso, totalizando oito alunos dos cursos de Ensino Médio-Técnico profissionalizantes mencionados, além de dois pesquisadores. O levantamento já foi realizado e seus resultados foram apresentados ao corpo docente, que está refletindo sobre possíveis mudanças no programa e nos materiais a serem elaborados/ utilizados. Além disso, os estudantes estão comprometidos com apresentações em eventos científicos e na elaboração de artigos científicos, a fim de divulgar tais resultados e contribuir para reflexões futuras. 
contribuindo, assim, para o desenvolvimento de capacidades de linguagem. No próximo item, princípios de tal arcabouço teórico são expostos e exemplificados.

\section{Princípios do Interacionismo Sociodiscursivo}

O ISD é uma corrente teórico-metodológica que começou a se constituir na década de 80 , com um grupo de pesquisadores genebrinos, que tomaram Vygotsky e Bakhtin como fontes de referência maior nos campos de desenvolvimento e linguagem respectivamente. Atualmente, há grupos de pesquisa em outras partes do mundo, como Portugal, Argentina e Brasil, que têm grupos com forte ligação com a Universidade de Genebra e seus pesquisadores. ${ }^{3}$

Ao reunificar a Psicologia e atribuir-lhe uma dimensão social, inicialmente, o grupo genebrino objetivava esclarecer as condiçôes de emergência e do funcionamento do pensamento consciente humano. Com sua ampliação, Bronckart chegou a dizer que "se trata de um projeto de construção de uma Ciência do Humano integrada (GUIMARÃES; MACHADO, 2007, p.16).”

Intencionando compreender a complexidade da materialização da comunicação em práticas sociais por textos, Bronckart (2003) iniciou o desenvolvimento de uma proposta metodológica de análise, que engloba os elementos ilustrados na FIG. 1, cujas definições são trazidas em seguida.

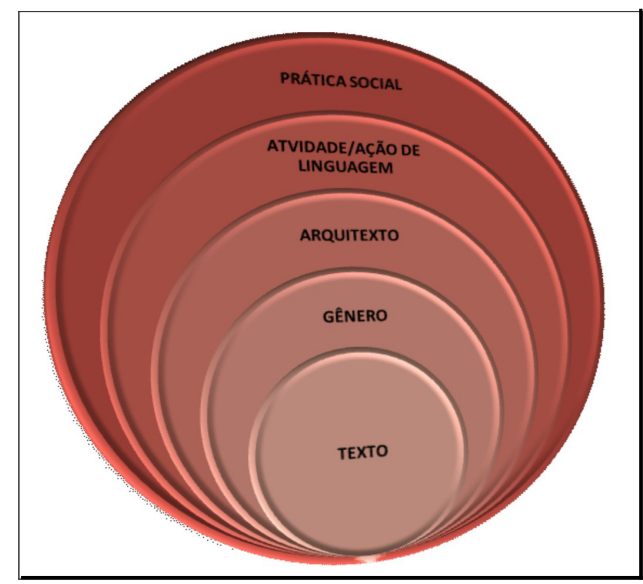

FIGURA 1 - Complexidade da materialização da comunicação nas práticas sociais por textos (BEATO-CANATO, 2009)

\footnotetext{
${ }^{3}$ Alguns exemplos são os grupos liderados por: Anna Rachel Machado (PUC-SP); Ana Maria de Mattos Guimarães (UNISINOS) e Vera Lúcia Lopes Cristovão (UEL).
} 
Para o ISD, linguagem designa um instrumento semiótico construído socialmente, fundador e organizador de processos psicológicos em suas dimensões especificamente humanas, tais como percepção, cognição, sentimentos e emoções (BRONCKART, 2006). Ação de linguagem, por sua vez, "designa o fato de que, em uma dada situação de comunicação, uma pessoa produz um texto, oral ou escrito, com outro objetivo, para obter um ou outro efeito (BRONCKART, 2010, p.169)." Essa ação de linguagem se realiza e se organiza, em partes, a partir das regras do gênero escolhido dentre os indexados por certa comunidade, ou seja, dentre os modelos reconhecidos como pertinentes e/ou adaptados a um conteúdo temático definido e a uma situação de interação determinada (BRONCKART, 2004). Nesse sentido, gêneros são mais que fôrmas, porque funcionam como molduras para a maneira com que agimos, pensamos e nos engajamos na interação (HYLAND, 2007). Vale relembrar que os gêneros textuais possuem estabilidade relativa (BAKHTIN, 2000), assim como as atividades humanas, e são produzidos por cada esfera social para atingir determinado objetivo em certa situação de comunicação.

O conjunto desses modelos compóe uma nebulosa de gêneros, ou o arquitexto, que é definido como o conjunto de modelos de gêneros em uso em determinada comunidade verbal, em uma dada época (BRONCKART, 2010). Entre esses modelos, o enunciador seleciona o mais adequado para alcançar seus objetivos e os efeitos esperados e produz seu texto, que é definido como uma unidade comunicativa socialmente construída e dependente de parâmetros múltiplos e heterogêneos (BRONCKART, 2003). Essa definição evidencia que, embora sua produção exija a mobilização de unidades linguísticas, o texto não é uma unidade linguística, mas, sim, comunicativa, porque suas condiçôes de abertura e de fechamento são determinadas pela ação que o gerou (BRONCKART, 2010).

Com relação aos níveis de análise, em texto publicado em 2010, Bronckart esclarece que a proposta do ISD procura dar continuidade à abordagem de Volochinov, na qual os textos deveriam ser analisados em uma perspectiva descendente, incluindo: 1) os tipos de interaçōes sociais, em seus contextos; 2) os gêneros de textos produzidos no quadro dessas interaçoes; e 3) as unidades e estruturas linguísticas observáveis no interior dos gêneros. Para dar continuidade, o ISD propõe diferentes níveis de análise, sendo eles: a) nível da ação de linguagem, que pode ser descrita e analisada sem que as propriedades linguísticas do texto sejam investigadas; b) nível do texto, tomado como unidade comunicativa, com a preocupação de compreender sua organização em partes determinada pelo gênero escolhido para sua produção; ec) nível dos tipos 
de discurso, que se ocupa em compreender as coordenadas que organizam o conteúdo temático, de forma explicitamente distanciada (disjunta) ou não (conjunta) da situação de produção e as instâncias de agentividade verbalizadas em relação com o agente produtor, sendo de implicação ou autonomia. Depois, unidades linguísticas (subconjuntos de tempos de verbos, de pronomes, organizadores, advérbios, modalização etc.) e modos de organização sintática são investigados; tais elementos traduzem ou exprimem esses mundos discursivos e permitem a identificação de quatro tipos de discurso: discurso interativo, discurso teórico, relato, narração; d) nível dos mecanismos de textualização, que se dedica ao conjunto de procedimentos linguísticos que servem para assegurar tanto a coerência temática de um texto (pela distribuição das unidades de conexão e de coesão nominal) quanto a coerência enunciativa (pela distribuição das vozes e das modalizações).

Uma sugestão de atividade didática que pode conscientizar o aluno a respeito da complexidade do gênero e afastar a possibilidade de percepção do texto como uma unidade linguística puramente ou do gênero como uma fôrma é a discussão em uma aula de vários textos, solicitando que os aprendizes os analisem e preencham uma tabela com as seguintes informaçôes: gênero textual, contexto, organização e conteúdo (resumo). O desejável é que os textos originais sejam disponibilizados para contribuir na análise solicitada. Uma característica da abordagem instrumental pode ser usada nessa atividade, que seria o uso de textos em diferentes línguas (francês, espanhol, italiano), para que o aluno discuta as estratégias usadas e o quanto é possível compreender de um texto, mesmo sem os conhecimentos da língua que eles gostariam de ter ou avaliam como imprescindíveis para compreender qualquer texto. Essa discussão contribui também para a percepção do texto como unidade comunicativa. As experiências de trabalho com essa atividade foram gratificantes, tendo incitado os alunos a tecer comentários e questionamentos.

Uma forma de trabalho com gêneros textuais em sala de aula que pode englobar elementos dos diferentes níveis de análise citados anteriormente foi proposta pelo grupo de Genebra e desenvolvido especialmente por Schneuwly e Dolz (2004) e por inúmeros pesquisadores brasileiros, como os Anais do SIGET, ${ }^{4}$ por exemplo, podem evidenciar. No próximo item, a proposta é apresentada.

\footnotetext{
${ }^{4}$ Internacionalizado em 2005, o Simpósio Internacional de Gêneros Textuais (SIGET) teve sua primeira edição em 2003, na Universidade Estadual de Londrina (Paraná) e é, atualmente, um dos eventos mais importantes da área, com ampla abrangência e relevância. Seus objetivos principais são: 1) congregar pesquisadores brasileiros e
} 


\section{Sequências Didáticas}

A maneira de organização proposta é em sequências didáticas (SD), definidas como "um conjunto de módulos escolares organizados sistematicamente em torno de uma atividade de linguagem dentro de um projeto de classe (DOLZ; SCHNEUWLY, 1998, apud CRISTOVÃO, 2009)", cuja finalidade geral é "o domínio, na produção e na recepção, dos gêneros de texto, na medida em que eles se constituem como instrumentos de adaptação e de participação na vida social/comunicativa (BRONCKART, 2010, p.172)."

O elaborador de uma SD precisa conhecer as características do gênero a ser didatizado e, para isso, o ISD prevê a construção de seu modelo didático, ou seja, um levantamento de suas características englobando os níveis mencionados previamente. Isso é fundamental para que uma SD consiga contribuir para o desenvolvimento de capacidades de linguagem, entendidas como "aptidões requeridas para a realização de um texto numa situação de interação determinada (DOLZ; PASQUIER; BRONCKART, 1993, p.30)". Didaticamente, elas são divididas em capacidade de ação (que prioriza o contexto), capacidade discursiva (que enfoca o conteúdo temático, a organização textual, os tipos de discurso e de sequência) e capacidade linguístico-discursiva (que trabalha com os mecanismos de textualização, responsáveis pela coerência temática e interativa do texto). Embora divididas didaticamente, as capacidades são mobilizadas de maneira integrada, para que a comunicação se efetive, por isso, um grupo de pesquisa do qual participo, Linguagem e Educação, ${ }^{6}$ utiliza uma engrenagem (FIG. 2) para ilustrá-las.

estrangeiros envolvidos em estudos sobre gêneros textuais; 2) discutir questôes teóricas e aplicadas relacionadas à pesquisa em gêneros textuais; 3) divulgar estudos teóricos e aplicados que possam oferecer diferentes enfoques e abordagens, contribuindo para releituras desse objeto de pesquisa; e 4) oportunizar a discussão de questôes relevantes para a construção de uma agenda política e pedagógica destinada a políticas governamentais. (Informaçōes disponíveis em: <http://www.cchla.ufrn.br/visiget/>. Acesso em: 21 mar. 2011.)

5 "Aptitudes requises pour la réalisation d'un texte dans une situation d'interaction déterminée [...]" (DOLZ; PASQUIER; BRONCKART, 1993, p. 30)

${ }^{6}$ Grupo de pesquisa cadastrado no CNPq e liderado pela Profa. Pós-Doutora Vera Lúcia Lopes Cristovão. É um grupo da Universidade Estadual de Londrina, formado por pesquisadores e estudantes de graduação, mestrado e doutorado, que toma os princípios do ISD como base de suas pesquisas e atua especialmente no ensinoaprendizagem e na formação de professores de línguas (estrangeiras). 


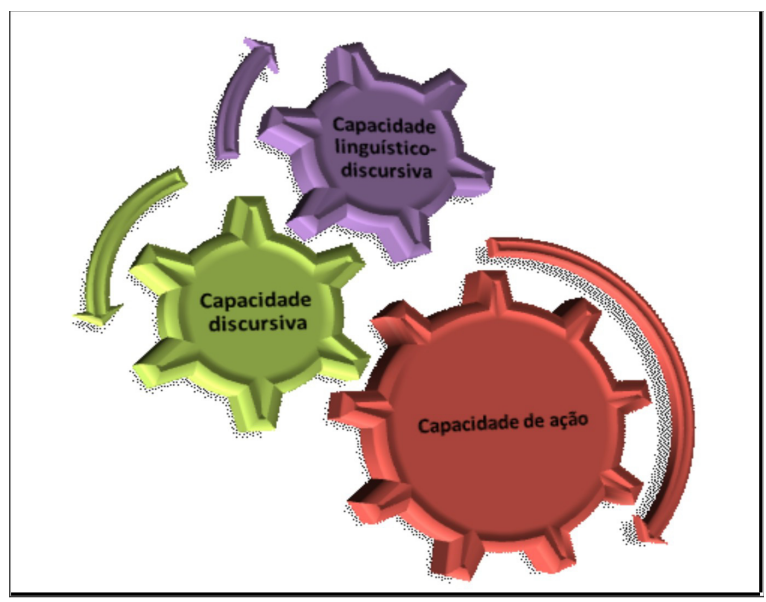

FIGURA 2 - Capacidades de linguagem (BEATO-CANATO, 2009)

O trabalho com SD é progressivo e espiralado e pode ser guiado por um tema ou por um objetivo geral. Ele pressupõe um primeiro contato com o gênero para observar os conhecimentos dos alunos e estabelecer as dificuldades a serem priorizadas. Em seguida, sugere a elaboração de módulos focados em aspectos específicos e o retorno ao geral, para perceber o desenvolvimento do aprendiz para agir na situação de comunicação específica.

Como Bronckart (2010) sinaliza, os objetivos sociopolíticos da política escolar devem ser prioritários e a teoria deve estar a serviço deles, o que significa que não se deve simplesmente aplicar uma teoria, mas, sim, fazer a transposição didática, escolhendo elementos teóricos que pareçam úteis e adaptando-os a cada contexto. Nesse sentido, ao elaborar uma coleção de livros didáticos de inglês para o Ensino Fundamental II, por exemplo, nós (CRISTOVÃO; BEATO-CANATO; FERRARINI; PETRECHE; ANJOS-SANTOS, 2009) fizemos adaptações à proposta de didatização de gêneros de Dolz e Schneuwly, procurando adequá-la ao contexto de ensino-aprendizagem de línguas estrangeiras no ensino regular brasileiro. $\mathrm{Na}$ mesma linha, esse artigo discute adaptações para a disciplina de inglês para fins específicos. No próximo item, uma SD é descrita com a intenção de ilustrar como esses conceitos podem ser aplicados em sala de aula. 


\section{Exemplos de trabalho em uma perspectiva interacionista sociodiscursiva em um curso de inglês para fins específicos}

Para ilustrar o trabalho com inglês para fins específicos a partir dos pressupostos do ISD, o material elaborado para abordar gêneros acadêmicos é trazido. A SD procura contribuir para o desenvolvimento de capacidades de linguagem específicas do meio acadêmico e foi elaborada por sugestão dos alunos e utilizada com o sétimo período do curso de Química do Instituto Federal de Educação Tecnológica (Campus Rio de Janeiro) - penúltimo período do curso e último período da disciplina Inglês para Fins Específicos, com quatro aulas semanais de quarenta e cinco minutos cada. Vale ressaltar que os alunos consideravam-se iniciantes, tinham cursado inglês 1 (com quatro aulas semanais de quarenta e cinco minutos cada) e inglês 2 (com 2 aulas semanais de quarenta e cinco minutos). A turma era relativamente pequena, com quatorze alunos.

Para o desenvolvimento das atividades, foi realizada uma pesquisa com professores da área específica que sugeriram o estudo a partir do portal <http://pubs.acs.org>, no qual se tem acesso a diferentes periódicos da área. O objetivo do material desenvolvido foi investigar as características de uma revista científica frequentemente utilizada pelo corpo docente da instituição como fonte de pesquisa, bem como resumos de artigos científicos da área e, finalmente, artigos científicos e a produção de pôster de apresentação em eventos.

O trabalho foi feito na sala de informática, possibilitando o trabalho individualizado, como é comum ao longo do desenvolvimento de pesquisas. A cada bloco de atividades uma discussão era realizada para que possíveis dúvidas fossem sanadas e outras informaçōes relevantes fossem colocadas.

Em se tratando do trabalho com o contexto, as duas primeiras atividades da SD podem ser ilustrativas. Para realizá-las, os alunos deveriam visitar o endereço: <http://pubs.acs.org> e apontar: a) o nome do website; b) sua origem; c) seus objetivos; d) o tipo de informação encontrável; o público-alvo. Em seguida, acessar a seção Journals $A-Z$ e responder as seguintes perguntas: a) Quais áreas de interesse o site cobre? b) Há algum periódico de seu interesse? Se afirmativo, qual e por quê?; c) Você acredita que estudantes de outros cursos da instituição se interessariam por algum dos periódicos disponibilizados? Justifique sua resposta; d) Você acredita que seus professores usam este website? Por quê (não)? 
A realização das atividades e as discussões geradas incentivaram a compreensão do contexto e a percepção de quanto ele determina as açôes de linguagem, conforme discute o ISD, possibilitando que o aluno notasse a relevância do portal e o quanto seu uso faz parte do cotidiano de pesquisadores, caso de boa parte dos professores da instituição e de vários estudantes que desenvolvem pesquisas, inclusive com o apoio de órgãos de fomento.

Após tais atividades, que englobam o portal como um todo (novamente dentro da proposta de trabalho do geral para o específico para retornar ao geral), atividade semelhante foi realizada com foco em um periódico específico da área de química, Accounts of Chemical Research. O que foi proposto é que o estudante visitasse o site do periódico e identificasse: a) a universidade responsável por ele; b) seus objetivos; c) os tipos de edições disponíveis; d) o total de citações em 2009; e e) se era um periódico indexado. As atividades buscaram levar os alunos a reconhecer outras características de um periódico.

Tendo explorado o aspecto contextual, a próxima etapa focalizou a parte discursiva ao propor a investigação da organização de abstracts com a análise de suas partes constitutivas e a ordem em que geralmente aparecem em um texto. Nesse momento, os estudantes puderam perceber a regularidade com que as partes aparecem e se organizam ao ler atentamente vários abstracts da seção ASAP, ou seja, os últimos publicados na revista, disponíveis exclusivamente online no momento em que os estudavam.

Ainda nessa fase, foi possível debater rapidamente a respeito das operaçóes psico-linguageiras que sustentam os textos, tanto as coordenadas quanto as instâncias de agentividade do produtor, compreendendo o tipo de discurso predominante, e relacionando-o ao estudo do contexto realizado previamente, dentro da perspectiva de funcionamento das capacidades de linguagem de maneira integrada, como discutido em item anterior que tratou dos princípios do ISD.

Considerando a complexidade dessa análise, os passos propostos por Bronckart $(2003$; 2010) foram seguidos, iniciando o trabalho com a elaboração de resumos dos textos lidos, o que possivelmente contribuiu para a compreensão dos planos gerais dos textos lidos e a forma com que seus conteúdos temáticos foram organizados. Em seguida, oralmente e conjuntamente, a análise mais aprofundada dos textos foi realizada, com foco em algumas estruturas linguísticas ilustrativas dos engajamentos discursivos, ou seja, da maneira com que os autores se implicavam/colocavam nos textos. Alguns elementos identificados foram: a ausência de unidades linguísticas referentes ao agente- 
produtor (pronomes pessoais, por exemplo) e ao espaço-tempo de produção; a ausência de frases não-declarativas (interrogativas e exclamativas); o tempo verbal predominante (presente do indicativo); a presença de voz passiva. Também foram observados os usos de organizadores textuais e modalizadores. A análise de tais características não causou dificuldades e possibilitou que os aprendizes percebessem as atitudes dos autores, colaborando para a compreensão dos textos de maneira mais profunda.

Como penúltima atividade dessa parte da SD, foi proposta uma discussão que procurava retomar o contexto e as características discursivas e ainda analisar as características linguístico-discursivas presentes. Essa organização foi pensada com a intenção de discutir como a língua é usada em função da comunicação almejada, como aponta Bronckart (2010). As questões propostas para discussão foram as seguintes: a) Por que um resumo de artigo científico (abstract) é produzido?; b) Para quem ele é produzido?; c) Qual é a importância de um texto ser indexado?; d) Por que o resumo é geralmente em inglês?; e) Você costuma ler resumos? Por quê?; e f) Falando sobre a linguagem usada, quais das afirmações a seguir são apropriadas? Marque-as e exemplifiqueas com trechos dos textos estudados: 1) Linguagem formal é usada; 2) Palavras de origem latina são comumente utilizadas; 3) Verbos frasais aparecem com frequência; 4) Concisão é desejável, por isso, há uma grande quantidade de sintagmas nominais; 5) Organizadores textuais são muito comuns e contribuem para guiar a leitura. A discussão possivelmente contribuiu para que o grupo percebesse, por exemplo, a importância do resumo em um artigo científico e também de sua produção em uma ou mais línguas estrangeiras, bem como a linguagem empregada e os motivos pelos quais determinados elementos da língua são preferidos em detrimento de outros.

É necessário apontar que diversos alunos encontraram obstáculos para realizar essa atividade, especialmente no que se refere à análise linguísticodiscursiva. Por esse motivo, a discussão foi longa, com a exploração de exemplos que ilustrassem melhor cada item apontado. Para ilustrar, a dificuldade para identificar palavras de origem latina e compreender que essa é uma qualidade da linguagem formal/acadêmica em língua inglesa pode ser mencionada. Os termos usados também causaram algumas dúvidas; alguns estudantes, por exemplo, não recordavam o significado de verbos frasais ou sintagmas nominais, que foram retomados e elucidados.

A última atividade dessa parte da SD propôs a leitura individualizada de um resumo escolhido pelo aluno e sua análise crítica englobando contexto, 
organização e linguagem, preparando-se para compartilhá-la com seus colegas na aula seguinte, que encerraria essa etapa do trabalho.

As aulas envolveram a turma de maneira geral e o interesse foi acima do esperado. No final do processo, os alunos comentaram que essa havia sido a parte mais relevante do curso com duração de três semestres, o que evidencia a produtividade da participação dos aprendizes na construção do planejamento dos cursos e o quanto um trabalho voltado para suas necessidades específicas de fato faz mais sentido e pode possibilitar maior desenvolvimento. Além disso, corrobora o que é defendido neste artigo, isto é, que é possível trabalhar com inglês para fins específicos em uma perspectiva interacionista sociodiscursiva.

\section{Considerações finais}

Como mencionado, o trabalho com línguas para fins específicos procura contribuir para que o aprendiz tenha condiçōes de utilizar determinada língua estrangeira de forma autônoma em situações comunicativas específicas. Da mesma maneira, o ISD preconiza um trabalho didático que contribua para o desenvolvimento de capacidades de linguagem necessárias para agir em contextos específicos. Com objetivos similares, é esperado que haja semelhanças entre as abordagens e, certamente, desenvolver um trabalho em uma abordagem interacionista sociodiscursiva não significa o abandono total das características da abordagem instrumental elecandas por Ramos (2005; 2009, no prelo), até pelo fato de existirem algumas semelhanças entre as perspectivas apresentadas.

Para ilustrar, duas características da abordagem instrumental que podem ser transportadas para uma abordagem interacionista sociodiscursiva são o trabalho com estratégias de leitura e com formação de palavras. No caso dessa última, ela seria tomada no ISD, como um elemento transversal da língua, ou seja, um item presente em praticamente a totalidade da arquitetura textual que pode ser trabalhado em qualquer gênero ou de maneira paralela à SD (DOLZ; GAGNON; TOULOU, 2008).

Como semelhanças entre as abordagens, é possível mencionar a preconização do trabalho com textos autênticos, a partir das necessidades dos alunos; a preocupação em colaborar para o desenvolvimento da autonomia do aprendiz; a defesa da exploração de elementos linguísticos relevantes para o texto; a crença de que os objetivos determinam a maneira com que o texto deve ser lido.

Por outro lado, há diferenças entre elas. Provavelmente a mais importante seja o desvio de foco do texto para o gênero textual e, consequentemente, a 
preocupação com a compreensão dos diferentes níveis apontados por Bronckart (2010). Outras diferenças talvez sejam a preocupação com a pluralidade de gêneros como instrumento para o ensino, o desenvolvimento de capacidades de linguagem, a progressão em espiral, o trabalho processual com alterações na complexidade das tarefas (CRISTOVÃO, 2009).

É possível notar que a proposta de Ramos (2004) se aproxima da proposta do ISD, que defende o foco em gêneros textuais, até pelo fato da pesquisadora, como ela mesma coloca, ter tido contato com a proposta genebrina. Algumas semelhanças são: a organização do material em torno de gêneros textuais; o trabalho com questóes contextuais (como determinadoras), discursivas e linguisticodiscursivas (nas palavras de Ramos, com contexto, organização retórica e características léxico-gramaticais); o trabalho de forma espiralada, partindo do geral para o específico e retornando para o geral; a preocupação em evitar que o gênero seja visto como fôrma e também em explorar exclusivamente textos autênticos; a importância dada à interação, em uma perspectiva vigotskiana.

Ao explicar a última fase de sua proposta, aplicação, Ramos (2004) coloca que é nesse momento que o que foi estudado em partes é tomado como um todo. Na proposta interacionista sociodiscursiva, diferentemente, há uma ênfase para que ao longo do trabalho o aluno, mesmo estudando aspectos específicos, perceba a totalidade. Em SD de produção textual, por exemplo, o aluno é sempre convidado a analisar um elemento específico de seu texto e, em seguida, avaliar se há mudanças mais globais a serem feitas.

Com relação a isso, dentre as exemplificaçôes de Ramos (2009), é perceptível que as características dos gêneros são apresentadas mais rapidamente, possivelmente, devido ao escasso espaço de tempo. Semelhantemente, algumas das SD que foram elaboradas para a disciplina de inglês instrumental no contexto apresentado pressupunham o trabalho em poucas aulas com um gênero em específico. Em alguns momentos, cheguei a nomear algumas delas de mini SD, porque eram desenvolvidas em uma única aula e procuravam englobar características contextuais, discursivas e ao menos um elemento lingüísticodiscursivo relevante. Todavia, outras SD eram mais longas e aprofundadas, o que dependia especialmente da relevância do gênero textual apontada pelos grupos.

O cuidado com a variedade de extensão das SD foi tomado em busca da rapidez pressuposta pela disciplina sem deixar de abordar os diferentes níveis descritos por Bronckart (2010), tais como o estudo de tipos de discurso e de sequência. Certamente, esse é um risco que exige um olhar atento para evitálo, pois, caso esses níveis não sejam abordados em nenhum momento, é possível que o aluno não alcance o grau de capacidade de linguagem esperado ou desejável. 
Contudo, o foco no contexto e no texto como unidade comunicativa já parece ser um grande avanço.

Concluindo, o importante é que o foco seja na articulação entre os processos de expressão e de estruturação, com os segundos a serviço dos primeiros, em oposição ao processo didático clássico, que centrava-se no domínio do código (estruturação gramatical) (BRONCKART, 2010). Tendo isso em vista, é possível trabalhar em uma abordagem interacionista sociodiscursiva, realizando as adaptaçōes necessárias ao contexto de trabalho.

\section{Referências}

ALMEIDA FILHO, J. C. P. de. Ontem e hoje no ensino de línguas no Brasil. In: STEVENS, M. T.; CUNHA, M. J. C. Caminhos e colheitas. Ensino e pesquisa na área de inglês no Brasil. Brasília: Editora da UnB, 2004.

BAKHTIN, M. Os gêneros do discurso. In: . Estética da criação verbal. Trad. Maria E. G. G. Pereira. São Paulo: Martins Fontes, 2000. p. 279-326. BEATO-CANATO, A. P. M. O desenvolvimento da escrita em lingua inglesa com o uso de sequências didáticas contextualizadas em um projeto de troca de correspondências. 2009. 307f. Tese (Doutorado em Estudos da Linguagem) Universidade Estadual de Londrina, 2009.

BRASIL. Ministério da Educação. Secretaria de Educação Fundamental. Parâmetros Curriculares Nacionais: terceiro e quarto ciclos do ensino fundamental: língua estrangeira/ Secretaria de Educação Fundamental. Brasília: MEC / SEF, 1998.

BRONCKART, J. P. Gêneros de textos, tipos de discurso e sequências. Por uma renovação do ensino da produção escrita. Letras, Santa Maria, v. 20, n. 40, p.163-176, jan./jun. 2010.

BRONCKART, J. P. Un retour nécessaire sur la question du développement. In: BROSSARD, M.; FIJALKOW, J. Vygotski et les recherches en éducation et en didactiques. Bordeaux: Presses Universitaires de Bordeaux, 2008. p. 237-250.

BRONCKART, J-P. Atividade de linguagem, discurso e desenvolvimento humano. Org. Anna Rachel Machado e Maria de Lourdes Meirelles Matencio. Trad. Anna Rachel Machado, Maria de Lourdes Meirelles Matencio et. al. Campinas: Mercado de Letras, 2006.

BRONCKART, J. P. Restrições e liberdades textuais, inserção social e cidadania. Conferência inaugural do XIV INPLA. PUC, São Paulo, 2004.

BRONCKART, J. P. Atividade de linguagem, textos e discursos: por um interacionismo sócio-discursivo. Trad. Anna Raquel Machado, Péricles Cunha. São Paulo: EDUC, 2003. 
CRISTOVÃO; V. L. L.; BEATO-CANATO, A. P. M.; FERRARINI, M.; PETRECHE, C. R. C.; ANJOS-SANTOS, L. Gear up. Curitiba: Base, 2009. (Coleção de quatro livros didáticos)

CRISTOVÃO, V. L. Sequências Didáticas para o Ensino de Línguas. In: DIAS, R.; CRISTOVÃO, V. L. L. (Org.). O livro didático de lingua estrangeira: múltiplas perspectivas. Campinas: Mercado de Letras, 2009. p. 305-344.

DOLZ, J.; GAGNON, R.; TOULOU, S. Production écrite et difficultés d'apprentissage. Geneve: Carnets des sciences de l'education, 2008.

DOLZ, J.; SCHNEUWLY, B. Gêneros e progressão em expressão oral e escrita - elementos para reflexões sobre uma experiência suíça (francófona). In: SCHNEUWLY, B.; DOLZ, J. et al. Gêneros orais e escritos na escola. Trad. e org. Roxane Rojo e Glaís Sales Cordeiro. Campinas: Mercado de Letras, 2004. p. 41-70. DOLZ, J.; PASQUIER, A.; BRONCKART, J-P. L'acquisition des discours: emergence d'une compétence ou apprentissage de capacités langagières? Études de Linguistique Appliquée, 102, p.23-37, 1993. p.23-37.

GUIMARÃES, A. M. de M.; MACHADO, A. R. Apresentação. In: GUIMARÃES, A. M. de M.; MACHADO, A. R.; COUTINHO, A. (Org.). O interacionismo sociodiscursivo: questões epistemológicas e metodológicas. Campinas: Mercado de Letras, 2007.

HYLAND, K. Genre and second language writing. 4. ed. Michigan: University of Michigan Press, 2007.

MOITA LOPES, L. P. da. Ensino de inglês como espaço de embates culturais e de políticas da diferença. In: GIMENEZ, T.; JORDÃO, C.; ANDREOTTI, V. (Org.). Perspectivas educacionais e ensino de inglês na escola pública. Pelotas: Educat, 2005. p.49-67.

RAMOS, R.C.G. ESP in Brazil: history, new trends and challenges. In: KRZANOWSKI, M. (Org.). Current developments in English for Academic and Specific Purposes in Developing, Emerging and Least-Developed Coutries. Reading: Garnet Publishing Ltda, 2009. p. 63-80. (versão prelo).

RAMOS, R. C. G. Instrumental no Brasil: a desconstrução de mitos e a construção do futuro. In: FREIRE, M.; ABRAHÃO, M. H. V.; BARCELOS, A. M. F. (Org.). Lingüistica Aplicada e Contemporaneidade. Campinas, SP: Pontes, 2005. p.109-123.

RAMOS, R. C. G. Gêneros textuais: uma proposta de aplicação em cursos de inglês para fins específicos. The ESPecialist, v. 25, n. 2, p. 107-129, 2004. 
ROMERO, T. R. de S. Inglês Instrumental enriquecido com ferramentas da Linguística Sistêmico-Funcional. Revista Caminhos em Linguistica Aplicada. UNITAU, v. 2, n. 1, 2010, p.29-35. Disponível em: <www.unitau.br/caminhosla>. Acesso em: 14 fev. 2011.

SCHNEUWLY, B. Genres et types de discours: considerations psychologiques et ontogénétiques. In: Coloque de l'université Charles-de-Gaulle III. Neuchâtel, 1994. Anais... Neuchâtel: Peter Lang, p. 155-173, 1994.

SCHNEUWLY, B.; DOLZ, J. Os gêneros escolares - das práticas de linguagem aos objetos de ensino. In: SCHNEUWLY, B.; DOLZ, J. et al. Gêneros orais e escritos na escola. Trad. e org. Roxane Rojo e Glaís Sales Cordeiro. Campinas: Mercado de Letras, 2004. p.71-91. 